\title{
Emerging supply chain of utilising electrical vehicle retired batteries in distributed energy systems
}

\author{
Rui Jing a,b, Junyao Wang ${ }^{\mathrm{c}}$, Nilay Shah ${ }^{\mathrm{a}}$, Miao Guo ${ }^{\mathrm{a}, \mathrm{d}, *}$ \\ a Department of Chemical Engineering, Imperial College London, London SW7 2AZ, UK \\ ${ }^{\mathrm{b}}$ Key Lab of Urban Environment and Health, Institute of Urban Environment, Chinese Academy of Sciences, Xiamen, China

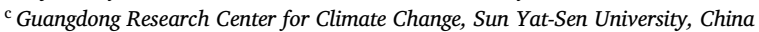 \\ ${ }^{\mathrm{d}}$ Department of Engineering, King's College London, Strand Campus, WC2R 2LS, UK
}

\section{A R T I C L E I N F O}

\section{Keywords:}

Electrical vehicle (EV)

Retired battery

Distributed energy system (DES)

Supply chain

Game theory

Optimisation model

\begin{abstract}
A B S T R A C T
Increasing electric vehicles (EV) penetration leads to significant challenges in EV battery disposal. Reusing retired batteries in distributed energy systems (DES) offers resource-circular solutions. We propose an optimisation framework to model the emerging supply chains and design strategies for reusing the retired EV batteries in DES. Coupling a supply chain profit-allocation model with a DES design optimisation model, the framework maximises the whole chain profit and enables fair profit distribution between three interactive sectors, i.e., EV, DES, dismantling and recycle (D\&R) sectors. Our research highlights the system implications of retired batteries on DES design and new modelling insights into incentive policy effectiveness. Our case study suggests significant potential value chain profits (2.65 million US\$) achieved by deploying $10.7 \mathrm{MWh}$ of retired batteries in the DES application with optimal retired battery price of $138 \mathrm{US} \$ / \mathrm{kWh}$. The revenue support on D\&R sector is suggested as a promising incentive scheme than tariff support.
\end{abstract}

\section{Background}

The electric vehicles (EVs) offer a promising low-carbon solution to decarbonise the transport sector [1]. However, the increasing production of EVs (above 5 million at 2020 in China) leads to significant challenges in EV battery disposal [2]. Typically, an EV lithium-ion (Li-ion) battery pack needs to be replaced when its capacity reduces to $80 \%$ of its rated capacity due to the safety and performance considerations [3]. By 2030 , the generated retired batteries could reach $708 \times 10^{3}$ ton in China, and the value is expected to rise with the flourishing of EV industry [4]. The expensive disposal process and low recycling rate (less than $2 \%$ ) cause environmental concerns e.g., active metals resource depletion [5]. With proper refurbishment, the retired EV batteries could be reused (also known as second-use) for a second life in stationary applications e.g., in distributed energy systems (DES), which has been suggested as a promising way to catalyse a resource-circular battery industry and create new supply chains for energy storage [6]. With the development of refurbishing or remanufacturing technologies [7], such an emerging supply chain not only leads to cost benefits for the entire industry, but also offers potential to reduce batteries' environmental impacts by extending life cycle of batteries as illustrated in Fig. 1, or avoidance of new battery production to meet demands for stationary energy sector [8]. To promote the reuse of retired EV batteries in stationary ap- plications, global automobile industry leaders have launched initiative projects e.g., BMW in Germany [9], Nissan in US [10], Renault in the UK [11], and BJEV in China [12].

\section{Literature review and knowledge gap}

This topic has attracted increasing research attention since 2010. Earlier studies have explored the retired batteries utilisation in the residential DES sector. Heymans et al. [13], discussed the economic performances and role of EV retired batteries for levelling the residential energy demands. Li et al. [14], optimised a residential microgrid considering the interaction between retired EV batteries and PV panels. Previous research investigated the deployment of the retired batteries to support renewable solar energy, such as published work by Tang et al. [15] and Assunção et al. [16]; feasibility studies were performed to understand the applications of retired batteries in commercial EV charging station [17], and industrial energy storage [18]; while the potential of implementing the retired batteries under a generalised DES context beyond "renewable + storage" systems remains largely unexplored.

The research efforts on evaluation of reusing retired batteries in stationary applications are further extended to wider perspectives more recently. Cusenza et al. [19] integrated lifecycle assessment approach to analyse the load match effects of reusing EV retired batteries. Canals

\footnotetext{
* Corresponding author at: Department of Chemical Engineering, Imperial College London, London SW7 2AZ, UK.

E-mail address: miao.guo@kcl.ac.uk (M. Guo).
} 


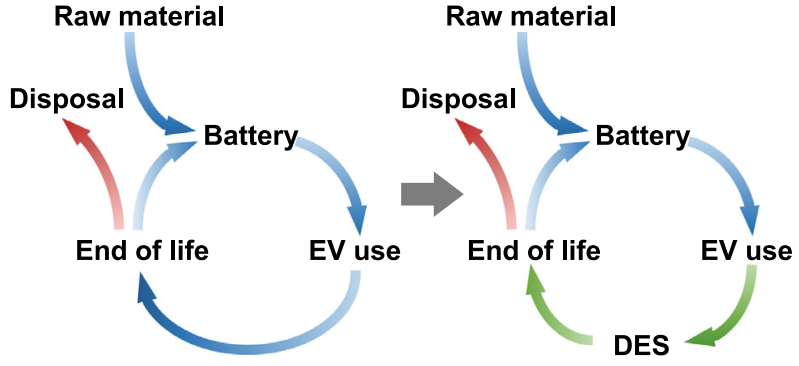

Fig. 1. Extending life cycle of EV batteries by reusing retired batteries in DES.

et al. [20] found that reusing second-life batteries as an energy aggregator to provide demand response services in European secondary electricity markets could achieve more profit than merely residential purpose. Tang et al. [21] further developed a game theory based optimisation model to evaluate social-economic-environmental impacts of the retired EV batteries industry and observed that the reward-penalty mechanism could contribute to a higher recycling rate. As an emerging concept, the published research studies have indicated the technical feasibility of using retired batteries in stationary applications.

Despite research efforts placed on evaluation of using retired batteries in stationary applications, few studies have been oriented from a whole supply chain perspective, whereas lack of whole system perspective may lead to a biased view of the profitability of reusing retired batteries in DES applications. A vital knowledge gap exists in understanding the interactions between the DES sector and its upstream and downstream sectors. Within this emerging supply chain, several key system implications of retired batteries' price, potential market volume, and technology deployment policies remain largely unexplored, which deserve further investigation.

To address knowledge gaps, we propose an integrative framework, for the first time, to model the emerging supply chains and design strategies for reusing the retired EV batteries in DES. Such emerging solution represents innovation in future energy transition and offers a promising supply chain to interlink EV battery and energy storage sectors through resource-circular technologies. By coupling a game theory approach [22] and a DES design optimisation model [23], the interaction of supply chain nodes, including government agencies, EV and battery manufacturing sectors, DES sectors, and dismantling and recycling (D\&R) sectors are modelled. Developing a case study on retired EV battery applications in China, we demonstrate the new insights such modelling framework can generate to inform decision-making on economic and technique aspects of utilising EV retired batteries in DES applications.

\section{Model framework}

We propose a framework integrating a supply chain profit-allocation model with a DES design optimisation model as illustrated in Fig. 2(a). The supply chain profit-allocation model considers the cascade utilisation of retired batteries from the EV sector in the stationary applications for energy storage of the DES sector, and final disposal by the D\&R sector. The whole supply chain profits are maximised while considering a fair profit-allocation among sectors, which is achieved by the Nash equilibrium type formulation [24] as structured in Fig. 2(b). Here, the fairness is defined as an equilibrium where all sectors involved in the supply chain achieve an acceptable or 'fair' allocation of total supply chain profit [25]. Fig. 2(c) illustrates a DES where the design optimisation model derives the cost-optimal solutions for DES energy network design, system configuration design, and dispatch strategy [26] equipped with new or retired batteries for 20 -year project lifetime. Beyond the typical "renewable + storage" system, we investigate system implications of utilising either new or retired batteries on the generalised DES design. This has been achieved by developing the DES optimisation model that covers renewable and non-renewable energy sources, energy network and exchange, and supply-demand co-design fulfilling the electricity, cooling and heating demands of a district with multiple buildings.

Eq. (1) defines the profit of each sector $\left(\pi_{\mathrm{EV}}, \pi_{\mathrm{DES}}\right.$ and $\left.\pi_{\mathrm{D \& R}}\right)$ in line with Fig. 2(b). The profit of EV sector is determined by the capacity of the retired batteries $\left(C A P^{\mathrm{RB}}\right)$ sold to the DES sector and the value difference between the retired battery sales price (price ${ }^{\mathrm{RB}}$ ) and corresponding costs for collection \& reassembling $\left(\mathrm{C}_{\mathrm{EV}}\right)$. The profit of DES is defined as the energy system cost savings from implementing retired batteries $\left(\mathrm{C}_{\mathrm{DES}}^{\mathrm{RB}}\right)$ instead of new batteries $\left(\mathrm{C}_{\mathrm{DES}}^{\mathrm{NB}}\right)$, and these two costs are optimised by the DES design optimisation model (DES model details in Method Section). As for D\&R sector, its profit is determined by the capacity of retired batteries $\left(C A P^{\mathrm{RB}}\right)$ discarded by the DES sector at the end-of-life, multiplied by per unit economic benefit (benefit ${ }^{\mathrm{D} \& \mathrm{R}}$ ) of final processing and valuable material recovery.

$\pi_{\mathrm{EV}}=C A P^{\mathrm{RB}} \times\left(\right.$ price $\left.e^{\mathrm{RB}}-\mathrm{C}_{\mathrm{EV}}\right)$

$\pi_{\mathrm{DES}}=C_{\mathrm{DES}}^{\mathrm{NB}}-C_{\mathrm{DES}}^{\mathrm{RB}}$

$\pi_{\mathrm{D} \mathrm{R}}=C A P^{\mathrm{RB}} \times$ benef it $^{\mathrm{D} \mathrm{R}}$

Based on these profits definitions, the capacity of retired batteries $\left(C A P^{\mathrm{RB}}\right)$ and sales price (price ${ }^{\mathrm{RB}}$ ) are two key decision variables that interlink all three sectors. The capacity of retired batteries sold by EV sector is equal to the capacity installed in DES and the capacity of batteries eventually discarded to the D\&R sector at the end-of-life. Hence, the capacity $\left(C A P^{\mathrm{RB}}\right)$ represents the potential market volume for the entire supply chain. The sales price of retired batteries (price ${ }^{\mathrm{RB}}$ ) for the EV sector is the same as the capital cost of retired batteries installation for the DES sector. The integrative model optimises these key decision variables with the defined parameters including $\mathrm{C}_{\mathrm{EV}}$, benefit ${ }^{\mathrm{D} \& \mathrm{R}}$ and techno-economic parameters for the DES design model (specified in the Method section).

The flowchart in Fig 3 illustrates how the components in the modelling framework are interlinked and resolved. In general, the modelling framework simultaneously optimises (1) the cost-efficient energy system design with retired batteries and (2) the fair profit allocation scheme for the modelled supply chain, to determine the optimal market volume and selling price of reusing EV retired batteries, as well as the potential profit of the whole supply chain. All model formulations are detailed in the Method section.

\section{Case study and optimal solutions}

We apply the proposed framework to evaluate the system implications of reusing EV retired Lithium-ion batteries for a DES application in an urban district in Shanghai, China. Six commercial buildings in this district represent a 20-year DES application to fulfilling their cooling, heating, and electricity demands equipped with retired batteries. Fig. 4 shows the model parameterisation in accordance with Fig. 3 including energy demands, energy tariffs, locations, etc. Fig. 4a-c demonstrates the typical annual energy demands, which reflect the variation in demand profiles in a typical year. Fig. 4d shows spatial distribution of six buildings, which impact the energy networks. The energy tariffs given in Fig. 4e affect both system design and dispatch strategies to achieve cost optimal system; solar radiation index in Fig. $4 \mathrm{f}$ impacts the renewable energy generation from rooftop PV panels. As defined by Eq. 1, the reassemble cost for the EV sector and per unit economic benefit for the D\&R sector are two given parameters to determine the key decision variables i.e. the capacity of retired batteries and sales price. In this case, we assume the reassemble cost for the EV sector as $27 \mathrm{US} \$ / \mathrm{kWh}$ and the economic benefit for the D\&R sector as $13.5 \mathrm{US} \$ / \mathrm{kWh}$ based on the recent market estimation $[27,28]$. The average capital cost of new batteries was assumed as $410 \mathrm{US} \$ / \mathrm{kWh}$ with a range of $250 \sim 670 \mathrm{US} \$ / \mathrm{kWh}$ [29]. The retired batteries are expected to have a lower capital cost than the new batteries; with proper refurbishment, both retired and new bat- 
(a)

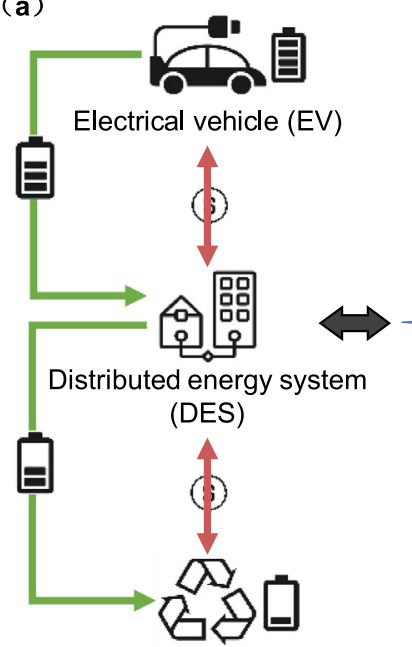

Dismantling \& Recycle (D\&R)

Supply chain profit-allocation model (c) Utility

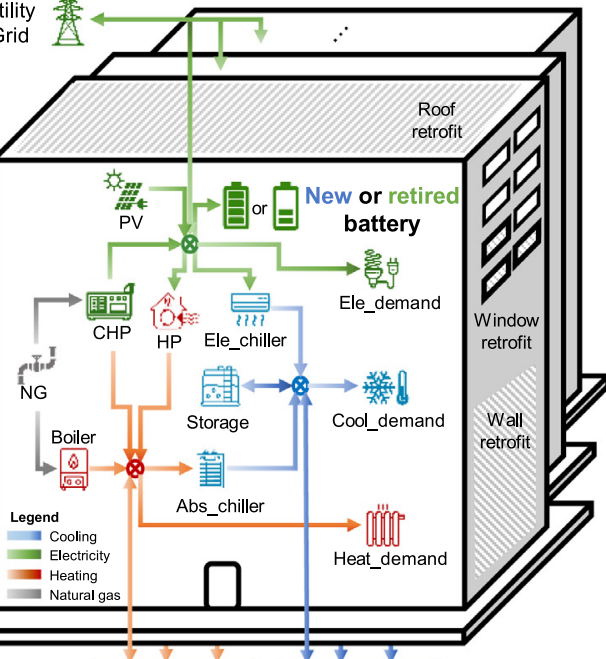

Heating network Cooling network

\section{DES design optimisation model}

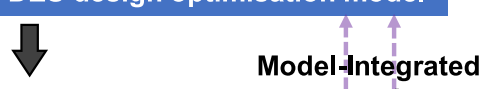

connections

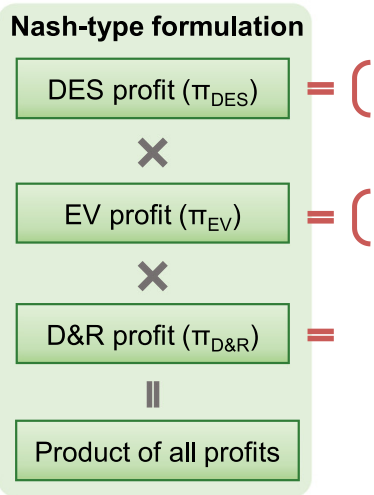

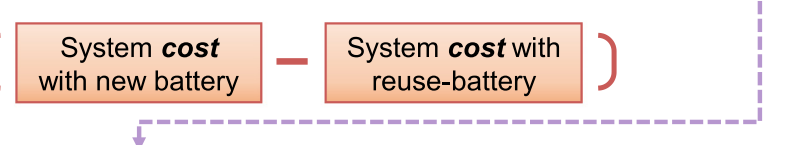

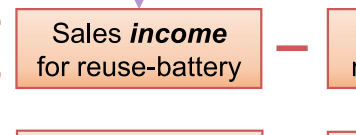

Valuable material

benefit

4
Collect \&

reassemble cost

Reuse-battery capacity

Fig. 2. Schematic of the proposed modelling framework for reusing EV retired batteries in DES. (a) shows the integration of the supply chain profit-allocation model with the DES design optimisation model. (b) illustrates the Nash-type formulation structure of the proposed framework with definitions of the profit for each sector, two implementation of incentive policies, and the connections for model integration. (c) illustrates the DES that the design optimisation model can achieve a cost-efficient energy system design that fulfilling electricity, cooling, and heating demand simultaneously. Abbreviation in DES design optimisation model: solar photovoltaic (PV), combined heating and power (CHP), heat pump (HP), natural gas (NG), electrical chiller (ele_chiller), and absorption chiller (Abs_chiller).

teries were assumed to have similar performance during the DES application, i.e., $93 \%$ charging/discharging efficiency, $2 \%$ self-discharge rate [3], and the consistency among cells. However, the retired batteries have shorter lifetime and replacements are required every 5-years during the DES application lifespan [16]. Note that these assumptions, particularly on cost values, are case specific and could be sensitive to future development of battery technologies and recycling technologies.

The model optimises profit allocation strategy from the market regulation perspective to enable the emerging supply chain of retired EV battery. The optimal solution with the maximum supply chain profit under the fair profit allocation strategy is shown in Fig. 5. The whole supply chain can achieve an overall profit of $\mathbf{2 . 6 5}$ million US\$ for this application, in which D\&R, EV, and DES sectors account for $6 \%, \mathbf{4 5 \%}$, and $49 \%$, respectively. The profit of the EV sector comes from the sales income of the retired batteries. The D\&R sector's profit relies on the market volume (i.e., installed capacity) of retired batteries. As for the D\&R sector, the larger capacity of retired batteries been adopted in the supply chain, the higher amount of valuable material can recycle for higher profits. The obtained optimal sales price of retired batteries is $138 \mathrm{US} \mathbf{\$} / \mathrm{kWh}$. The market volume of retired batteries is projected as 10.7 MWh, which is equivalent to reusing the battery pack of approx- imately 515 hybrid electric passenger cars (HEPC), 258 battery electric passenger cars (BEPC) or 74 battery electric commercial vehicles (BECV). The optimisation solution is derived based on the average energy density of retired batteries, i.e., $75 \mathrm{wh} / \mathrm{kg}$ (with the range of 60 $90 \mathrm{wh} / \mathrm{kg}$ ), average weights of battery pack for HEPC, i.e., $275 \mathrm{~kg}$ (with range of 150-400 kg), BEPC, i.e., $550 \mathrm{~kg}$ (with range of $300-800 \mathrm{~kg}$ ), and BECV, i.e., $1900 \mathrm{~kg}$ (with range of $800-3000 \mathrm{~kg}$ ) [30].

\section{DES design with retired EV batteries}

The lower capital cost by using retired batteries not only directly affects the profit of DES but also leads to different DES designs as shown in Fig. 6(a), which contributes to the profit allocation of DES sector. Due to the lower price of retired batteries than new batteries, a significantly higher capacity of batteries is adopted within the system, i.e., 10.7 MWh of retired batteries compared to $1 \mathrm{MWh}$ of new batteries. Hence, the peak/off-peak electricity tariff, as well as the feed-in tariff, are efficiently utilised to power the district to reduce the DES costs, and also gain more income by selling electricity back to the grid during the peak period. Consequently, the installed capacity of CHP reduces significantly in the retired batteries cases in comparison with new bat- 


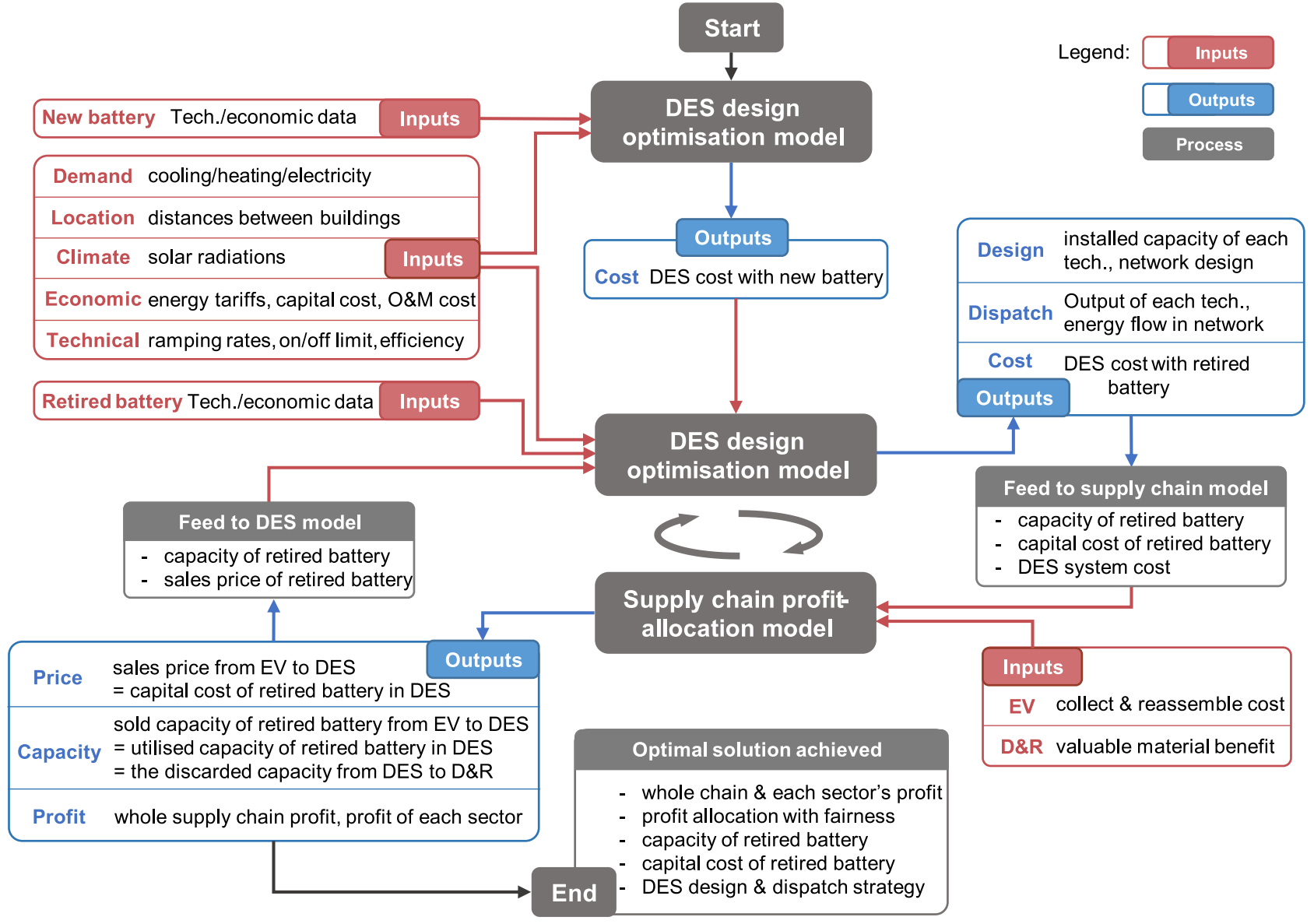

Fig. 3. Interlink and workflow of the proposed modelling framework. The overall workflow starts with resolving the DES design optimisation model with the new battery; the optimal DES solution with the new battery is considered as a parameter as defined in Fig. 2(b). Then we optimise the DES design with retired battery, the obtained solutions for installed capacity and capital cost of the retired battery, as well as the DES system cost, are fed into the supply chain profit-allocation model to optimise the profit of the whole supply chain considering profit-allocation fairness. The updated solution on installed capacity and capital cost of the retired battery are fed back to the DES design optimisation model iteratively. Finally, the optimisation loop ends at the Nash equilibrium point with an optimal solution achieved.

teries case. The lower capacity of CHP installation further leads to a lower heating supply, which results in an $10 \%$ increased investment on energy-saving strategies (i.e., more advanced retrofit options been applied). Thus, the capacity differences of heating/cooling energy supply technologies are insignificant for the two cases under investigation.

The 10.7 MWh capacity of retired batteries not only impacts the design of DES significantly but also influences the operational strategy of DES. Fig. 6(b) illustrates the operational strategy of retired batteries. In the morning, to reduce the self-discharge and fully utilise the off-peak tariff, battery charging happens $2-3 \mathrm{~h}$ before the peak periods (starting from 8 a.m.), and then the batteries discharge the stored electricity during the following 4-5 h. In the afternoon, the batteries are charged for 2-3 $\mathrm{h}$ with a normal tariff before the evening peak periods (starting from 6 p.m.), then the batteries discharge for DES utilisation over the peak periods.

\section{Trade-off between maximum profit and fairness}

The above-mentioned optimal solution is considered as the baseline case, in which the D\&R sector only shares $6 \%$ of the total profit, while other two sectors both account for over $40 \%$ of total profit. Here we assess the trade-off between fairness and profit maximisation across the value chain. Our model enables evaluating possible scenarios by configuring different profit distributions as shown in Fig. 7(a-c), where con- straints are introduced to vary the profit-sharing ratio of a given sector (shown by $\mathrm{x}$ axis). The following insights have been generated:

(1) As shown in Fig. 7(a), the maximum of total profit for the D\&R sector is achieved in the baseline case, where DES and EV sectors share over $45 \%$ of total profit with the remaining $6 \%$ profit allocated to the $\mathrm{D} \& \mathrm{R}$ sector. When the D\&R sectors' profit is further reduced from $6 \%$ to $3 \%$, the lost profits of the D\&R sector are not captured by other sectors but result in the decline in total profit for the wholesupply chain. Considering the scenarios on the right-hand side of the baseline case, the profits of both DES and EV sectors decrease significantly to fulfill the constraints of increasing the share of D\&R sector, which leads to the total profit drop. The underlying reason for these observations is that the theoretical maximum profit of the D\&R sector is one order of magnitude smaller than that of other sectors based on the profit definitions in this study. Thus, in every scenario, the D\&R sector has reached or almost reached its maximum profit. Hence, to fulfill the constraint of increasing the share of D\&R sector's profit, the total profit of the whole supply chain has to be reduced. Additionally, the price of retired batteries drops with the increase in D\&R sector's profit share.

(2) A similar analysis of mandatory profit re-distribution is conducted for DES sector, which leads to different results compared to the D\&R sector. Although an increase in the DES sector's profit also leads to a reduction of total profit, the decline is relatively minor compared to the results from the D\&R sector. More interestingly, when the DES 


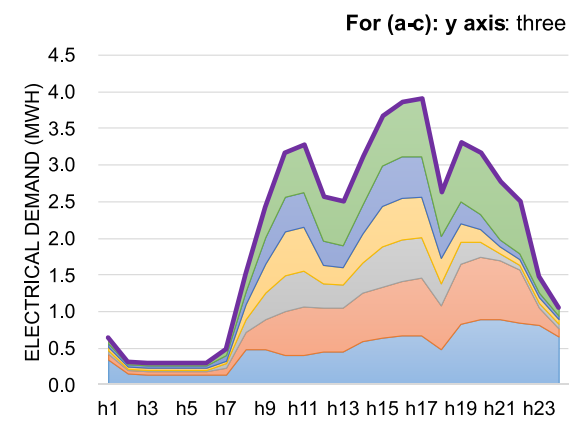

(a)

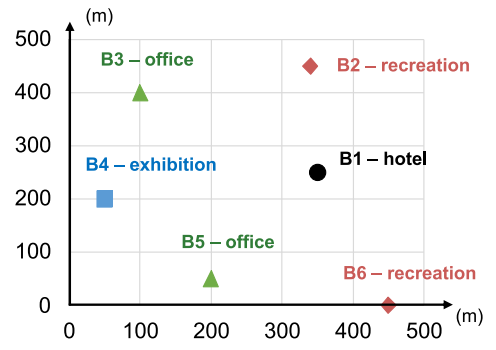

(d)

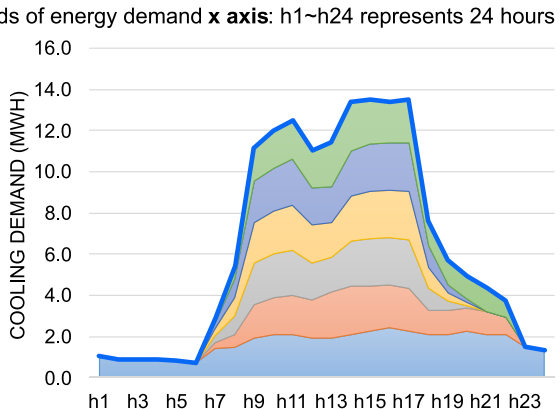

(b)

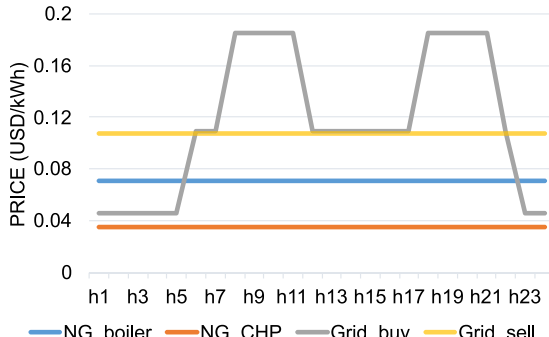

(e)

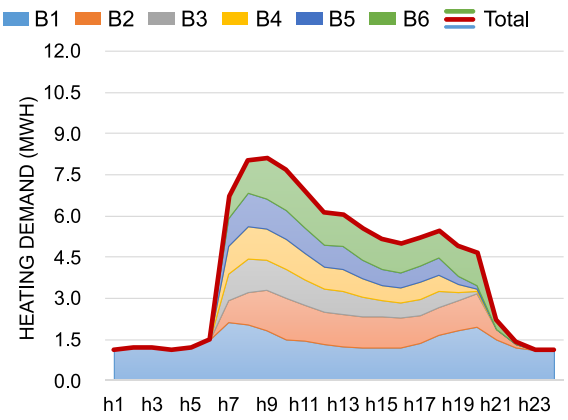

(c)

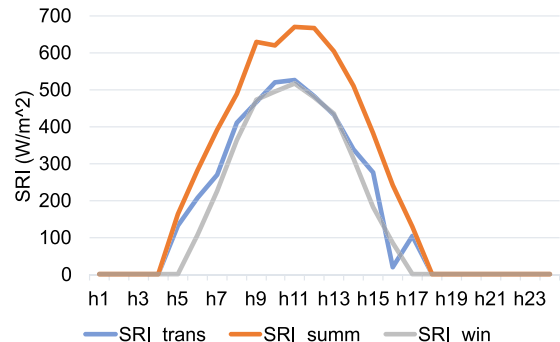

(f)

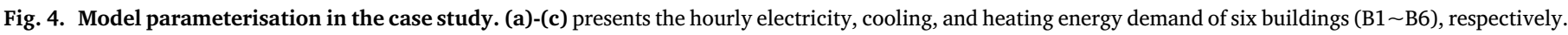

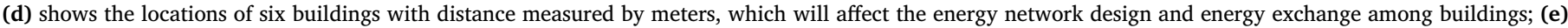

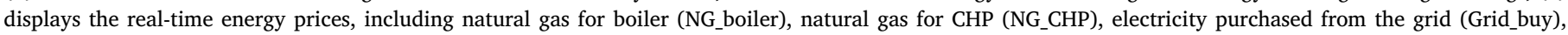

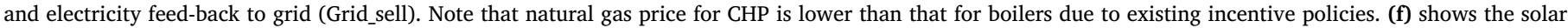

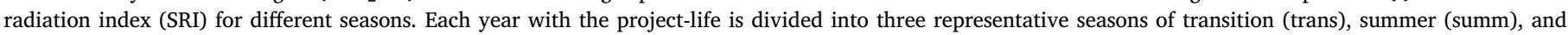
winter (win). Detailed inputs are presented in Supplementary SI-1.

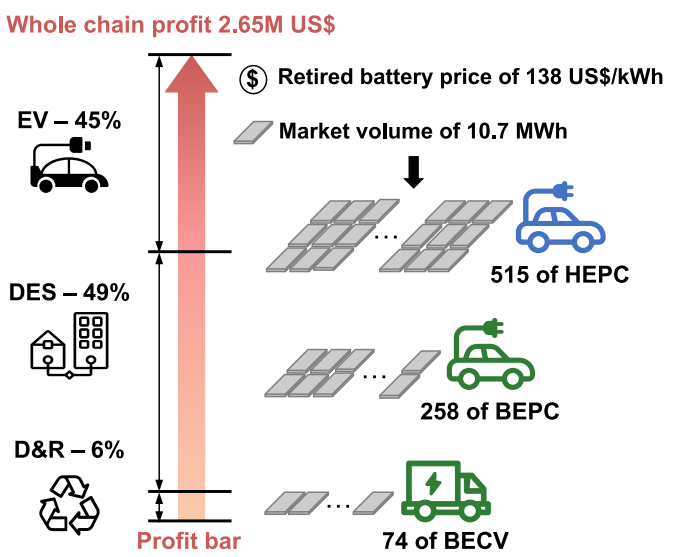

Fig. 5. Optimised whole supply chain profit, profit allocation scheme, retired battery price, and market volume of retired battery utilised in the case study.

sector's profit is forced to decline to $40 \%$, the total profit goes up slightly. As the D\&R sector tends to reach its maximum profit level, the slight increase in total profit can be attributable to the rising EV sector profit.

(3) Fig. 7(c) suggests that the variation of EV sector's profit share does not significantly affect the total profit. This can be explained by the variation in EV sectoral profit being efficiently offset by the DES sectoral profit (the D\&R sector's profit is still close to its maximum). Two interesting scenarios are marked by red circles in Fig. 7(b and c), which imply the less fair but profit-maximised solutions achieved when EV sector, DES sector and D\&R sector account for $55 \%, 40 \%, 5 \%$ of total profit, respectively. In comparison with the profit-maximisation solution, the baseline case (i.e., EV, DES and D\&R sectors account for $49 \%, 45 \%$, and 6\%, respectively) represents a fairer strategy for all supply chain players.
Overall, our results show that a "fairer" profit share scheme could be achieved with the drop of the total supply chain profit; and the tradeoff exists between achieving a fairer market and maximised total profit with dominant players. In the meantime, Fig. $7(\mathrm{a}-\mathrm{c})$ suggests that the price of retired batteries goes up along with the increment of EV sectoral profit and the drop of DES sectoral profit, and vice versa; compared to two other sectors, the D\&R sector tends to reach its maximum profit within a narrow range. These observations could inform decisionmaking on an effective scheme to incentivise this emerging supply chain.

\section{Policy implications}

Policy schemes are expected to promote the new technology penetration and regulate the markets [31]. Different technology deployment policies could be summarised and expressed as several key schemes [32], i.e., direct subsidy, revenue support, tax reduction, government loan, tariff support, green product purchasing, and certificate trading gain. Based on the observations in last section, here we present two scenarios to evaluate the effectiveness of revenue support policies for the low-profit D\&R sector and the tariff support policies for the DES sector.

\section{Revenue support on the dismantling and recycle $(D \& R)$ sector}

The revenue support can enable the D\&R sector to obtain extra income from recycling retired batteries, i.e., benefit ${ }^{\mathrm{D} \& \mathrm{R}}$ goes up. As illustrated in Fig. 8(a), a higher profit share of D\&R sector can be expected with the increase in revenue support. More importantly, a rising total profit and a fairer profit share among each player are also observed. When the revenue support reaches $40 \$ / \mathrm{kWh}$, the profit shares of the DES sector, EV sector and D\&R sector are $45 \%, 35 \%$, and $20 \%$, respectively. Meanwhile, the price of retired batteries remains around 130 to $150 \$ / \mathrm{kWh}$. This scenario suggests that revenue support for the D\&R 


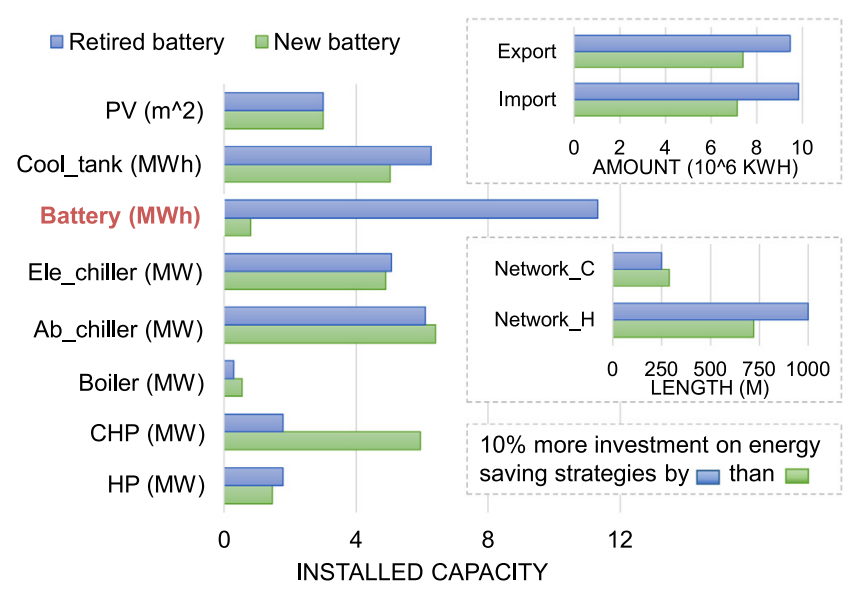

(a)

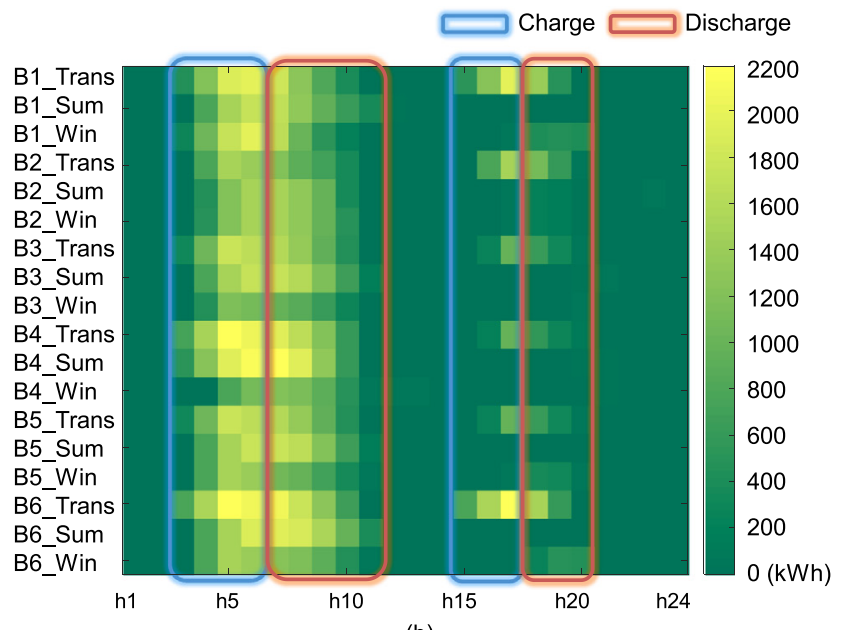

(b)

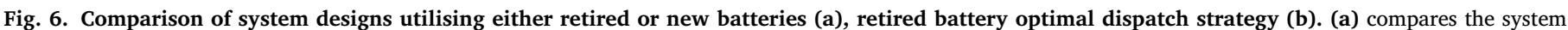

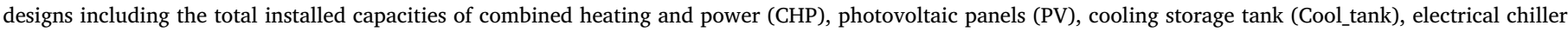

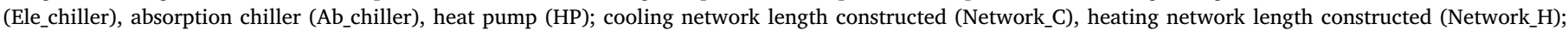

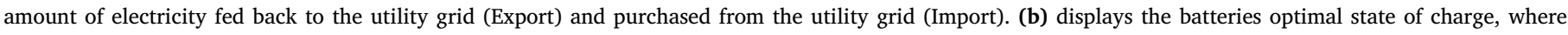

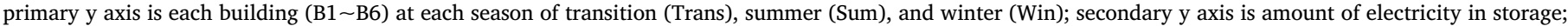
$\mathrm{x}$ axis represents $24 \mathrm{~h}$.

sector contributes to the improvement of total profit and a fairer profit distribution.

\section{Tariff support on DES sector}

It is interesting that the tariff support does not boost the total profit or fairness of profit share as expected. Tariff support for DES sector here is defined as a scheme that enables the DES to feed electricity back to national grid at a more competitive price during the peak periods. In fact, increasing the feed-in tariff price contributes to the promotion of batteries but not for retired batteries. As shown in the third y axis in Fig 8(b), the installed capacity of new batteries increases significantly with the increase in feed-back tariff price. This leads to a higher capacity of new batteries and much lower energy cost of DES. However, based on the profit definition, if the DES energy cost including new batteries is low, the profit of implementing retired batteries declines instead. Hence, the total profit does not increase. Additionally, the price of retired batteries is not significantly affected by the tariff support, varying between 125 and $150 \$ / \mathrm{kWh}$.

\section{Discussion and limitations}

\section{Potential of the retired EV batteries as a resource-circular solution}

Coupling game theory approach and DES design optimisation, we modelled the interaction of three sectors involved the emerging supply chain for retired EV battery re-use in urban DES. Our case study on a district with six commercial buildings in China demonstrates that a market volume of 10.7 MWh retired batteries can achieve significant supply chain profit (2.65 million US\$). Compared to the DES whole lifecycle (including capital and 20-year operation) cost of 31 million US\$, the supply chain profit is $8.3 \%$ of the DES whole lifecycle cost. The projected optimal sales price for the retired batteries sales price is 138 US $\$ / k W h$, which agrees with the price range reported in previous research (see supplementary Table S5). However, the supply chain profit, market volume and price of the retired EV batteries in this study only represent the insights from a specific case study, which may vary with variation in system parameters e.g. costs of battery reassembling, types of stationary applications.

\section{Impacts on DES design}

Our results suggest that retired EV batteries instead of new batteries can lead to significantly different design and operational strategy of DES. Due to the lower cost of retired batteries, the DES will install lower CHP capacity for onsite generation while installing a higher capacity of batteries and interact with the grid much more actively right before the peak period compared to the case of new batteries. A significant decline in energy cost of the DES can be expected by utilising the retired batteries, which could further be functional for peak shaving.

\section{Trade-off between maximum profit and fairness}

By mandatory re-distribution the profit, we found a trade-off between a fairer market and maximised supply chain profit with dominant players. The proposed framework allows quantitative analysis on different profit allocation scenarios. Since the maximum profit of D\&R sector (upper limit) is lower than other two upstream sectors, enforcing a "fairer" supply chain may lead to a reduced total profit across the supply chain. Such modelling evidence provides policy insights into key factors to regulate supply chains and enable retired battery adoption.

\section{Policy implications}

We develop a tool to understand how policies could promote the industry of utilising retired batteries in DES. The revenue support on D\&R sector improves the total supply chain profit and leads to a fairer profit distribution, showing that the revenue support policy has the potential to support the D\&R sector breaching its upper limit of profit. The profitability of the supply chain grows with D\&R sectoral profits. With the development of battery recycling technology and the increasing concerns on resource scarcity, the benefit of recycling valuable material is expected to increase, which could further promote the whole supply chain. By contrast, although tariff support is regarded as a practical policy to incentivise the market penetration of batteries in stationary applications, it is not effective for the retired batteries. This could be explained by the decrease in marginal cost-savings of retired batteries, as a consequence of tariff support which reduces the cost of using new batteries. These observations not only provide valuable insights but also 


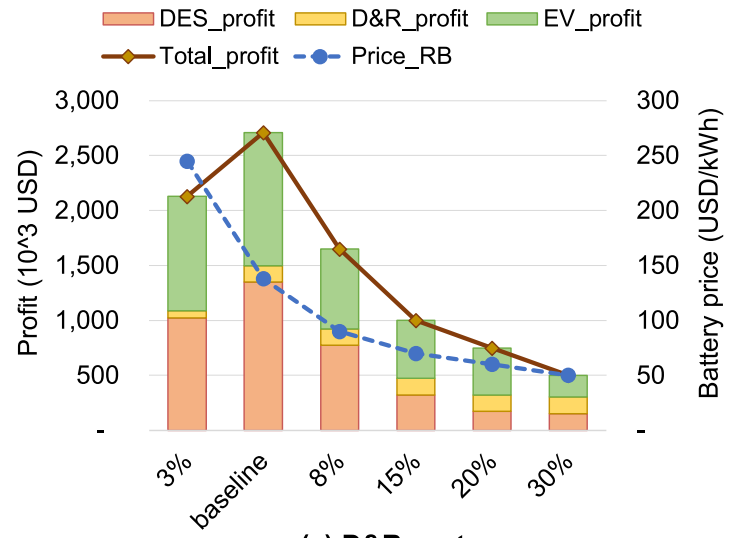

(a) D\&R sector

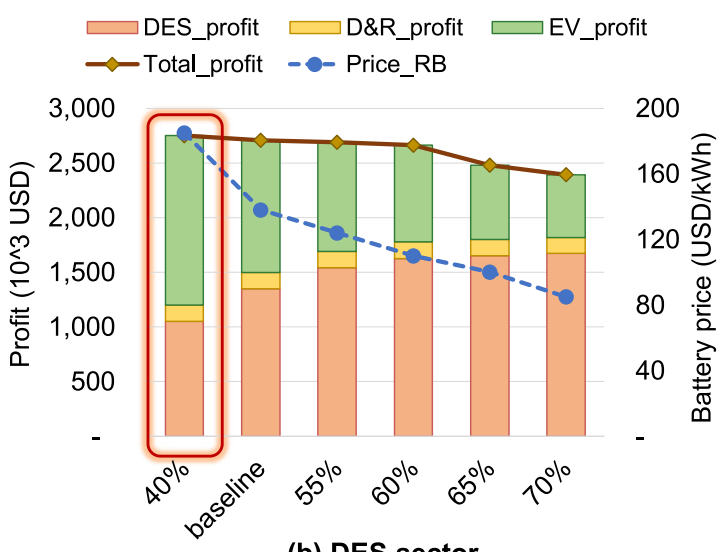

(b) DES sector

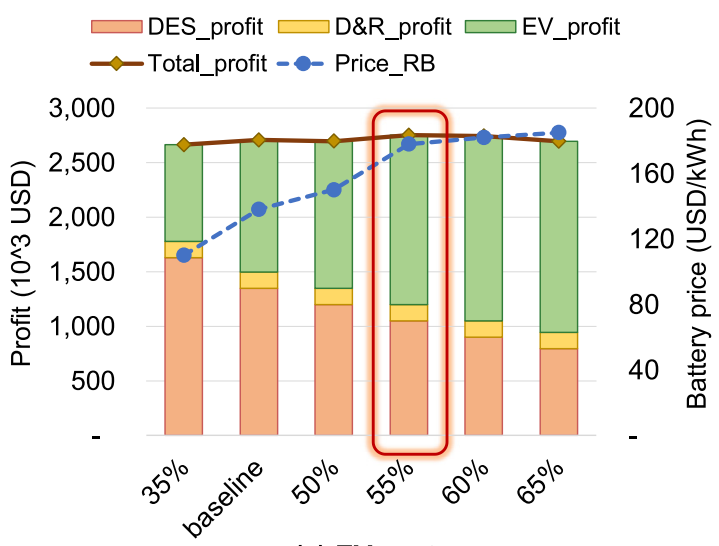

(c) EV sector

Fig. 7. Profit variations with different mandatory profit share for different sectors. a-c, increase profit share mandatory for (a) D\&R sector, (b) DES sector, (c) EV sector. $\mathrm{x}$ axis: different percentage of profit share mandatory assigned to D\&R sector (a), to DES sector (b), and to EV sector (c), respectively. Primary y axis: values of profit. Secondary y axis: price of retired batteries (Price_RB) achieved in different mandatory profit share scenarios.

importantly highlight how the proposed framework can inform policymaking on effective incentive scheme design.

\section{Limitations}

To enable research focused on retired battery optimal price, we have modeled reassemble cost for EV sector and economic benefit for D\&R sector as parameters, the assumed economic parameters were intro-

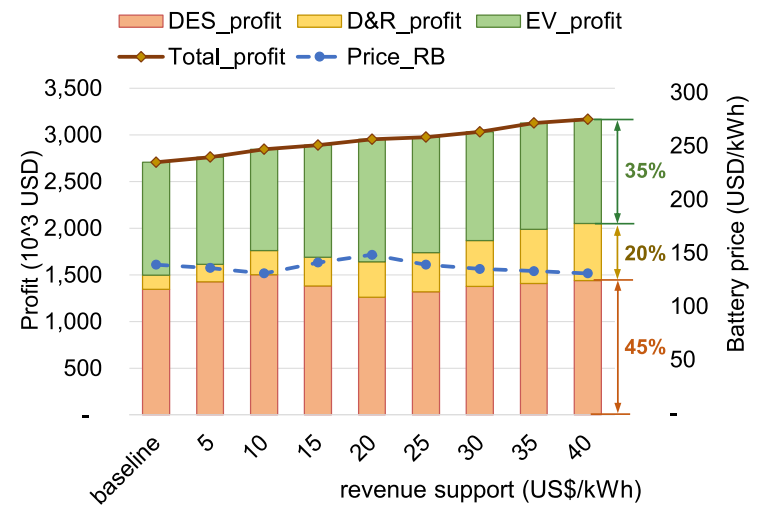

(a)

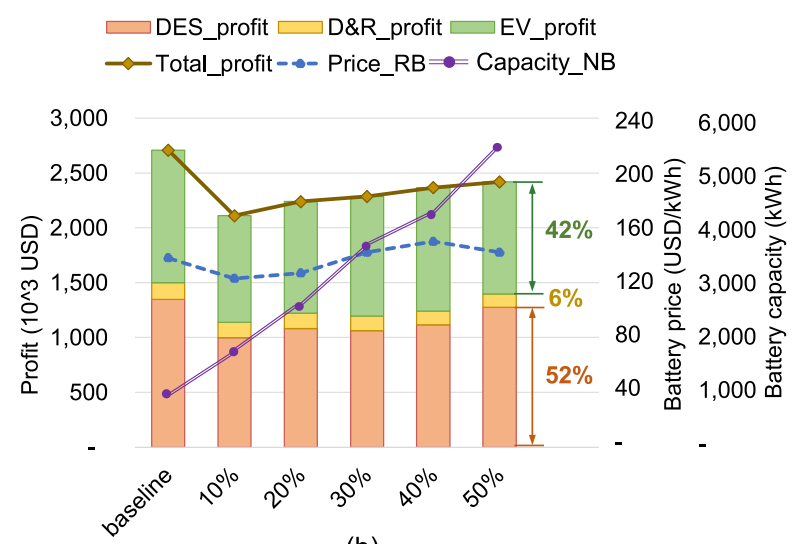

(b)

Fig. 8. Profit share when revenue support on D\&R sector and tariff support on DES sector. a-b, revenue support on D\&R sector (a), Tariff support on DES sector (b). In (a), $\mathrm{x}$ axis: subsidy amount $(\$ / \mathrm{kWh})$, primary y axis: profit archived of each sector, secondary y axis: retired battery price (Price_RB). In (b), $\mathrm{x}$ axis: different percentage of increase on feed-in tariff, primary y axis: profit archived of different sector, secondary y axis: price of retired battery (Price_RB), third y axis: installed capacity of new battery (Capacity_NB).

duced due to lack of reliable data source. In future research, with further penetration of retired EV batteries in DES applications, such parameterisation could be obtained from market price (or alternatively, they could be defined as variables to investigate their variation and optimal solutions).

\section{Conclusion and future perspectives}

The increasing number of electric vehicles (EV) leads to significant challenges in the disposal of EV retired batteries. Under a circular economy context, new supply chains are emerging to reuse the EV retired batteries for stationary DES applications, which enables the multiple sectors to benefit from cost-effective energy supply and battery reuse. To advance the understanding of system implications of retired batteries price, market volume and technology deployment strategies, we present an optimisation framework which integrates a supply chain profit-allocation model with a DES design optimisation model. The developed modelling framework not only optimises supply chain profit and allocation strategies but also captures the design and flexible operation of batteries in DES with hourly temporal resolution.

The case study in Shanghai shows a great potential of reusing the retired batteries in stationary application in urban areas. This has been demonstrated by a significant capacity (10.7 MWh retired batteries) and a supply chain profit of 2.65 million US\$ in a 6-building urban district. Our case study also suggests that EV and DES sectors tend to dominate 
the supply chain profit share by $45 \%$ and $49 \%$, respectively, whereas the D\&R sector shows the trend reaching its maximum profit. Our modelling results demonstrate that the policy support on the D\&R sector has the potential to increase both whole chain profit and profit share fairness. However, the effectiveness of technology deployment policy is worth modelling exploration - the policy incentive for new batteries may not be effective for the retired EV batteries. Additionally, more realistic investigations considering real operational data from car manufacturers would be valuable.

Overall, our research presents a mathematical modelling tool to inform decision-making on the emerging supply chain of reusing retired batteries in DES applications. Several emerging research frontiers could be further explored in future research:

(1) The proposed modelling framework is extensible to take into account the technical constraints of retired EV batteries, e.g. extra space requirements or higher maintenance requirements of retired batteries in comparison with new batteries. Such technical constraints could be formulated as either monetary or technical parameters in the model. The framework can also be expanded to explore multi-criteria decision-making considering environmental sustainability and economic viability, as well as simulate the interaction and competition between market players.

(2) The insights generated from this study informs decision-making on retired battery price which enables optimal supply chain profits and fairness of profit allocation. However, the developed modelling framework can be further adapted to other optimisation problems to inform decision-making in other sectors, e.g. optimal assembly costs for $\mathrm{EV}$ sector and economic benefits for D\&R sector.

(3) The modelling framework developed in this study is generally applicable to inform decision-making in retired EV batteries in stationary applications. We presented an urban central case study as it represents a potential site for reusing retired EV batteries due to high energy intensity and complementary demand profiles of neighbouring buildings. In future research, wider applications under global context including rural, urban fringe areas, and different regions could be modelled where the model parameterisation could be reconfigured to reflect local demand profiles, energy costs, and market maturity.

\section{Methods}

\section{Parameter and variable definitions}

A modelling framework has been developed to integrate a supply chain profit-allocation model with a DES design optimisation model. All the parameters and variables in this study are defined in Table 1 whereas the parameterisation is given in Supplementary Information Table SI-1.

\section{DES design optimisation model}

We developed a spatial-temporal MILP optimisation model to assess the technical and economic feasibility of utilising retired batteries in DES design. The model follows a bottom-up structure that optimises the system design and operational strategy simultaneously [33]. It offers flexible energy design options that all buildings in the case district can build their own energy systems, equip battery storage technologies, implement energy-saving measures, inter-connected as local networks, and interact with the macro grid [34]. We model the system operation with hourly resolution. The operation of all devices, state-of-charge for energy storage, and local and macro energy exchanges are captured with hourly resolution for representative days in typical seasons.

DES model inputs. The developed model is parameterised with inputs including (a) spatial representation of buildings, (b) hourly time horizon, (c) real-time electricity and natural gas tariffs, (d) solar radiation index, (e) electricity, cooling and heating energy demand, (f) technical parameters, e.g., efficiencies and energy saving potential, ramp rates, on/off limits, (g) economic parameters, e.g., capital cost, O\&M cost, (h) climate parameters, e.g., solar radiations. Detailed parameters in this case are given in Supplementary SI-1. A slightly higher maintenance cost for the retired batteries than new batteries is also considered [20],

DES model outputs. The outputs from the model include (a) energy network design and energy exchange; (b) system configurations, sizing, and operation strategies; (c) adopted energy saving strategies; (d) optimised energy system cost when equipped with new or retired batteries.

DES model objective. This model minimises the energy system cost including the capital cost and the discounted operational cost (interests rate (r) of 6\%) for a 20-year project as derived in Eq. 2.

$C_{\mathrm{DES}}^{\mathrm{NB} / \mathrm{RB}}=C A P E X+\sum_{y=1}^{20}\left(F C_{y}+M C_{y}+G C_{y}\right) \times(1-r)^{y}$

The capital cost (CAPEX) includes capital cost of all energy device and pipework, as well as cost of implementing energy-saving measures for roof, window and wall as shown in Eq. (3a). Note that only one option for each energy saving strategy for each building is allowed as constrained by Eq. (3b).

$C A P E X=\sum_{i, t} C A P_{i, t} \times C_{t}^{\mathrm{CAP}}+\sum_{i, j \neq i} D X_{i, j} \times C_{\mathrm{pipe}}^{\mathrm{CAP}}+\sum_{s^{\prime}, i, k^{\prime}=1,2,3} \varphi_{s^{\prime}, i, k^{\prime}} \times \mathrm{C}_{i, s^{\prime}, k^{\prime}}^{\mathrm{CAP}}$

$\sum_{k^{\prime}=1,2,3} \varphi_{s^{\prime} i, k^{\prime}} \leq 1$

All the operational cost (i.e., $F C, M C$, and $G C$ ) are discounted to the base year. Since we use typical day to simulate the hourly operation of DES while assume energy demands remain unchanged for each type of typical day at different years, the subscript of y is not displayed for the simplicity of model description. Fuel cost $(F C)$ is the cost of gas consumption by all devices as derived in Eq. 4 .

$F C=\sum_{i, s, h}\left(\frac{E_{i, s, h}^{\mathrm{CHP}}}{\eta_{\mathrm{CHP}}} \times C_{h}^{\mathrm{NG}-\mathrm{CHP}}+\frac{Q_{i, s, h}^{\mathrm{b}-\text { heat }}}{\eta_{\mathrm{b}}} \times C_{h}^{\mathrm{NG}-\mathrm{b}}\right)$

Maintenance cost $(M C)$ can be calculated by the unitary maintenance cost of each technology ( $\left.C^{\text {maint }}\right)$ multiplying the energy output from one certain device accordingly, as formulated in Eq. 5.

$$
M C=\sum_{i, s, h}\left(E_{i, s, h}^{\mathrm{pv} / \mathrm{CHP}}+Q_{i, s, h}^{\mathrm{hp} / \mathrm{b}-\mathrm{heat}}+Q_{i, s, h}^{\mathrm{ec} / \mathrm{ac}-\mathrm{cool}}+Q_{i, s, h}^{\mathrm{in}-\mathrm{st}}+E_{i, s, h}^{\mathrm{in}-\mathrm{st}}\right) \times C_{t}^{\text {maint }}
$$

The grid cost (GC) includes electricity purchasing cost minus the revenue of feed-back as shown in Eq. 6.

$G C=\sum_{i, s, h}\left(C_{h}^{\mathrm{im}} \times E_{i, s, h}^{i m}\right)-\sum_{i, s, h}\left(C_{h}^{\mathrm{ex}} \times E_{i, s, h}^{\mathrm{ex}}\right)$

DES model constraints. The model constraints include electricity, cooling, and heating energy balances (i.e., supply-demand balance), operation constraints (e.g., ramping and energy conversion), storage constraints (i.e., thermal and battery storage), utility grid connections (i.e., buy and sell electricity to the macro-grid), and network constraints (i.e., logical constraints on energy network design and operation). The constraints are detailed below.

DES model - Energy balances. The energy balances include electrical balance, heating balance and cooling balance. Eq. (7) presents the electricity balance, where battery charge and discharge are considered. Eq. (8) presents the heating balance, where energy exchange among buildings, energy exchange loss, and potential heating demand reduction by implementing energy saving strategies are modelled. Similar with the heating balance, Eq. (9) presents the cooling balance.

$E_{i, s, h}^{\mathrm{dem}}=E_{i, s, h}^{\mathrm{st}-\mathrm{out}}+E_{i, s, h}^{\mathrm{pv}}+E_{i, s, h}^{i m}+E_{i, s, h}^{\mathrm{cHP}}-E_{i, s, h}^{\mathrm{ec}}-E_{i, s, h}^{\mathrm{ex}}-E_{i, s, h}^{\mathrm{hp}}-E_{i, s, h}^{\mathrm{st}-\mathrm{in}}$ 
Table 1

Nomenclature for optimisation modelling framework.

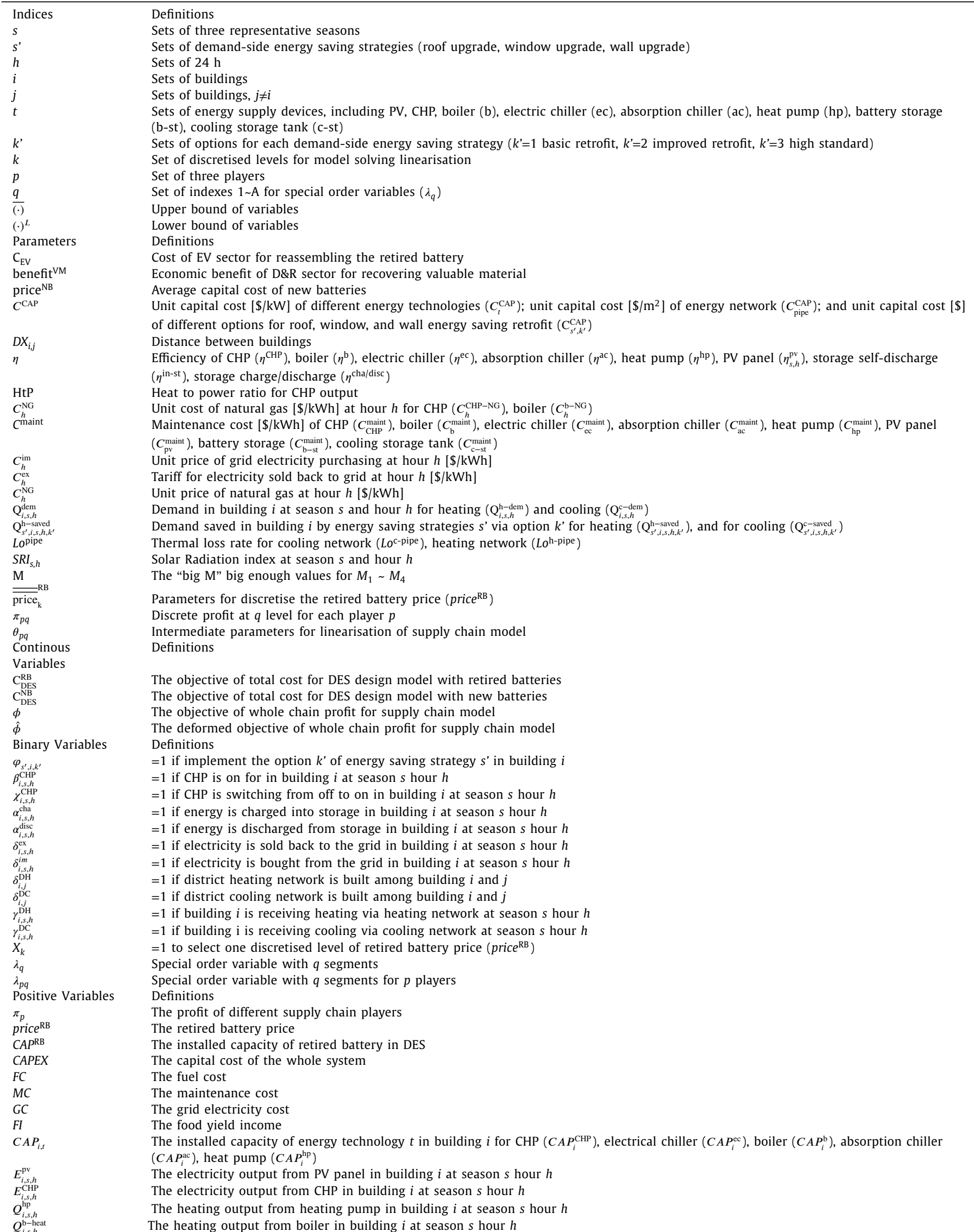




\begin{tabular}{|c|c|}
\hline$Q_{i, s, h}^{\text {ac-cool }}$ & The cooling output from absorption chiller in building $i$ at season $s$ hour $h$ \\
\hline$Q_{i, s, h}^{\text {ecchool }}$ & The cooling output from electric chiller in building $i$ at season $s$ hour $h$ \\
\hline$Q_{i, s, h}^{i, s-n}$ & The cooling stored in storage tank in building $i$ at season $s$ hour $h$ \\
\hline$E_{i, s, h}^{i, s, n}$ & The electricity stored in battery in building $i$ at season $s$ hour $h$ \\
\hline$E_{i, s, h}^{i, s, h}$ & The electricity bought from the grid in building $i$ at season $s$ hour $h$ \\
\hline$E_{i, s, h}^{\text {ex }}$ & The electricity sold back to the grid in building $i$ at season $s$ hour $h$ \\
\hline$Q_{i, s, s, h}^{\operatorname{lifh}(i, j)}$ & The heating flow from building $i$ to $j$ at season $s$ hour $h$ \\
\hline$Q_{j, j, i, s, i, h}^{h+s, i}$ & The heating flow from building $j$ to $i$ at season $s$ hour $h$ \\
\hline$Q_{i, j, s, h}^{\mathrm{cf}(i, j)}$ & The cooling flow from building $i$ to $j$ at season $s$ hour $h$ \\
\hline$Q_{j, i, s, h}^{\text {ctis,in }}$ & The cooling flow from building $j$ to $i$ at season $s$ hour $h$ \\
\hline$Q_{i, s, h}^{\text {re-heat }}$ & The heating output from CHP in building $i$ at season $s$ hour $h$ \\
\hline$Q_{i, s, h}^{\text {cha }}$ & The cooling charge into cooling storage in building $i$ at season $s$ hour $h$ \\
\hline$Q_{i, s, h}^{\text {disc }}$ & The cooling energy discharged in building $i$ at season $s$ hour $h$ \\
\hline$E_{i, s, h}^{\mathrm{st}-\mathrm{in}}$ & The electricity charge into battery storage in building $i$ at season $s$ hour $h$ \\
\hline$E_{i, s, h}^{\mathrm{st}-\mathrm{out}}$ & The electricity discharged in building $i$ at season $s$ hour $h$ \\
\hline$N G_{i, s, h}^{b}$ & The natural gas consumed by boiler in building $i$ at season $s$ hour $h$ \\
\hline$N G_{i, s, h}^{\mathrm{CHP}}$ & The natural gas consumed by CHP in building $i$ at season $s$ hour $h$ \\
\hline$Z_{k}$ & The dummy variable for linearisation of the product of two continuous variables \\
\hline
\end{tabular}

$$
\begin{aligned}
& Q_{i, s, h}^{\mathrm{ac}-\mathrm{heat}}+\sum_{j \neq i} Q_{i, j, s, h}^{\mathrm{hf}(i, j)}+Q_{i, s, h}^{\mathrm{h}-\mathrm{dem}}-\sum_{s^{\prime}, k^{\prime}=1,2,3} \varphi_{s^{\prime}, i, k^{\prime}} \times \mathrm{Q}_{s^{\prime}, i, s, h, k^{\prime}}^{\mathrm{h}-\text { saved }}=Q_{i, s, h}^{\mathrm{re}-\mathrm{heat}} \\
& +Q_{i, s, h}^{\mathrm{hp}}+Q_{i, s, h}^{\mathrm{b}-\mathrm{heat}}+\sum_{j \neq i} Q_{j, i, s, h}^{\mathrm{hf}(j, i)} \times\left(1-L o^{\mathrm{h}-\mathrm{pipe}}\right) \\
& Q_{i, s, h}^{\mathrm{cha}}+\sum_{j \neq i} Q_{i, j, s, h}^{\mathrm{cf}(i, j)}+Q_{i, s, h}^{\mathrm{c}-\mathrm{dem}}-\sum_{s^{\prime}, k^{\prime}=1,2,3} \varphi_{s^{\prime}, i, k^{\prime}} \times \mathrm{Q}_{s^{\prime}, i, s, h, k^{\prime}}^{\mathrm{c}-\text { saved }}=Q_{i, s, h}^{\mathrm{disc}} \\
& +Q_{i, s, h}^{\mathrm{ec}-\mathrm{cool}}+Q_{i, s, h}^{\mathrm{ac}-\mathrm{cool}}+\sum_{j \neq i} Q_{j, i, s, h}^{\mathrm{cf}(j, i)} \times\left(1-L o^{\mathrm{c}-\mathrm{pipe}}\right)
\end{aligned}
$$

DES model - Operation constraints. As formulated in Eq. (10a)-(e), at each time-step, the output of all devices should not be greater than the installed capacity accordingly; and the energy conversions are defined in Eq. (10f)-(j).

$$
\begin{aligned}
& E_{i, s, h}^{\mathrm{CHP}} \leq C A P_{i}^{\mathrm{CHP}} \\
& E_{i, s, h}^{\mathrm{ec}-\mathrm{cool}} \leq C A P_{i}^{\mathrm{ec}} \\
& Q_{i, s, h}^{\mathrm{b}-\text { heat }} \leq C A P_{i}^{\mathrm{b}} \\
& Q_{i, s, h}^{\mathrm{ac}-\text { cool }} \leq C A P_{i}^{\mathrm{ac}} \\
& Q_{i, s, h}^{\mathrm{hp}} \leq C A P_{i}^{\mathrm{hp}} \\
& Q_{i, s, h}^{\mathrm{re}-\mathrm{heat}}=\mathrm{HtP} \times E_{i, s, h}^{\mathrm{CHP}} \\
& Q_{i, s, h}^{\mathrm{ec}-\mathrm{cool}}=\eta^{\mathrm{ec}} \times E_{i, s, h}^{\mathrm{ec}} \\
& Q_{i, s, h}^{\mathrm{ac}-\mathrm{cool}}=\eta^{\mathrm{ac}} \times Q_{i, s, h}^{\mathrm{ac}-\mathrm{heat}} \\
& Q_{i, s, h}^{\mathrm{hp}}=\eta^{\mathrm{hp}} \times E_{i, s, h}^{\mathrm{hp}} \\
& Q_{i, s, h}^{\mathrm{b}-\mathrm{heat}}=\eta^{\mathrm{b}} \times N G_{i, s, h}^{b}
\end{aligned}
$$

Several specific operation constraints are implemented particularly for CHP system to avoid low part-load conditions. As given in Eq. 11, the minimum part load constraint is set at $30 \%$ of full capacity to avoid CHP operating at a low load range when the engine is in operation mode.

$E_{i, s, h}^{\mathrm{CHP}} \leq \beta_{i, s, h}^{\mathrm{CHP}} \times M_{1}$

$E_{i, s, h}^{\mathrm{CHP}} \geq\left(\beta_{i, s, h}^{\mathrm{CHP}}-1\right) \times M_{2}+0.3 \times C A P_{i}^{\mathrm{CHP}}$
To avoid frequently switching on/off of the CHP, the startup frequency is limited to once per day as constrained by Eq. 12 .

$\sum_{h} \chi_{i, s, h}^{\mathrm{CHP}} \leq 1$

$\chi_{i, s, h}^{\mathrm{CHP}} \geq \beta_{i, s, h}^{\mathrm{CHP}}-\beta_{i, s, h-1}^{\mathrm{CHP}}$

$\chi_{i, s, h}^{\mathrm{CHP}} \leq 1-\beta_{i, s, h-1}^{\mathrm{CHP}}$

$\chi_{i, s, h}^{\mathrm{CHP}} \leq \beta_{i, s, h}^{\mathrm{CHP}}$

To avoid drastic variation of CHP's power output, the output difference between last and this time-step is limited to $50 \%$ of the installed capacity (Eq. 13).

$E_{i, s, h}^{\mathrm{CHP}}-E_{i, s, h-1}^{\mathrm{CHP}} \leq 0.5 \times C A P_{i}^{\mathrm{CHP}}$

$E_{i, s, h-1}^{\mathrm{CHP}}-E_{i, s, h}^{\mathrm{CHP}} \leq 0.5 \times C A P_{i}^{\mathrm{CHP}}$

DES model - Storage constraints. We model both battery and cooling storage. Eq. (14a)-(e) is given as an example to illustrate the cooling storage constraints, whereas similar constraints apply to other storage devices.

$Q_{i, s, h}^{\text {in-st }}=\eta^{\text {in-st }} \times Q_{i, s, h-1}^{\text {in-st }}+\eta^{\text {cha }} \times Q_{i, s, h}^{\text {cha }}-Q_{i, s, h}^{\text {disc }} / \eta^{\text {disc }}$

$Q_{i, s, h}^{\mathrm{in}-\mathrm{st}} \leq C A P_{i}^{\mathrm{st}}$

$Q_{i, s, h}^{\text {cha }} \leq \alpha_{i, s, h}^{\text {cha }} \times \overline{Q_{i, s, h}^{\text {cha }}}$

$Q_{i, s, h}^{\mathrm{disc}} \leq \alpha_{i, s, h}^{\mathrm{disc}} \times \overline{Q_{i, s, h}^{\mathrm{disc}}}$

$\alpha_{i, s, h}^{\mathrm{disc}}+\alpha_{i, s, h}^{\text {cha }} \leq 1$

DES model - Grid connection. The power exchange between utility grid and the integrated energy system is defined in Eq. 15.

$E_{i, s, h}^{\mathrm{ex}} \leq \delta_{i, s, h}^{\mathrm{ex}} \times \overline{E_{i, s, h}^{\mathrm{ex}}}$

$E_{i, s, h}^{\mathrm{im}} \leq \delta_{i, s, h}^{i m} \times \overline{E_{i, s, h}^{\mathrm{im}}}$

$\delta_{i, s, h}^{\mathrm{ex}}+\delta_{i, s, h}^{i m} \leq 1$

DES model - Network constraints. The energy exchanges via cooling and heating network are similar from the modelling perspective, as constrained below. The heating transfer can only take effect when two 
buildings are connected by heating pipework as defined in Eq. (16a). Moreover, only connection between two buildings is allowed as constrained in Eq. (16b).

$\sum_{j \neq i} Q_{i, j, s, h}^{\mathrm{hf}(i, j)} \leq \delta_{i, j}^{\mathrm{DH}} \times \overline{Q_{i, j, s, h}^{\mathrm{hf}(i, j)}}$

$\delta_{i, j}^{\mathrm{DH}}+\delta_{j, i}^{\mathrm{DH}} \leq 1$

Similarly, cooling energy can only transfer when cooling pipework exists as defined in Eq. (17).

$\sum_{j \neq i} Q_{i, j, s, h}^{\mathrm{cf}(i, j)} \leq \delta_{i, j}^{\mathrm{DC}} \times \overline{Q_{i, j, s, h}^{\mathrm{cf}(i, j)}}$

$\delta_{i, j}^{\mathrm{DC}}+\delta_{j, i}^{\mathrm{DC}} \leq 1$

Meanwhile, building (i) cannot receive and transfer heating/cooling energy to other buildings ( $j$ ) simultaneously at each time step (Eq. (18a)(d)).

$\sum_{j \neq i} Q_{i, j, s, h}^{\mathrm{cf}(i, j)} \leq \gamma_{i, s, h}^{\mathrm{DC}} \times M_{3}$

$\sum_{j \neq i} Q_{j, i, s, h}^{\mathrm{cf}(j, i)} \leq\left(1-\gamma_{i, s, h}^{\mathrm{DC}}\right) \times M_{3}$

$\sum_{j \neq i} Q_{i, j, s, h}^{\mathrm{hf}(i, j)} \leq \gamma_{i, s, h}^{\mathrm{DH}} \times M_{4}$

$\sum_{j \neq i} Q_{j, i, s, h}^{\mathrm{hf}(j, i)} \leq\left(1-\gamma_{i, s, h}^{\mathrm{DH}}\right) \times M_{4}$

\section{Supply chain profit-allocation model}

We developed the supply chain profit-allocation model to maximise the profit of whole supply chain considering profit allocation fairness. Eq. 1 in the Model framework defines the profit for EV, DES, and D\&R sectors, respectively. Eq. (19a) formulates an objective function to maximise the summation of all sectors' profits. This objective function represents the centralised optimisation solutions leading to maximised supply chain profit, but it may lead to an unfair profit distribution. Here, we introduce Nash-type objective function as formulated in Eq. (19b) to ensure profit allocation fairness. This Nash-type formulation maximises the overall profits as the product of each sector's profit to achieve fair profit allocation, in the meantime, it offers flexibility to evaluate different profit distribution strategies [24,25].

$\phi=\sum_{p} \pi_{p}$

$\phi=\prod_{p}\left(\pi_{p}-\pi_{p}^{\mathrm{L}}\right)$

where the subscript p denotes supply chain nodes i.e. EV sector, DES sector, and D\&R sector; the superscript L represents lower bound.

Supply chain model outputs. The outputs from the model include (a) retired batteries' sales price, (b) market volume of the retired batteries utilised (i.e., installed capacity of retired batteries in the DES application), (c) total profit of whole supply chain and the profit share of each sector.

\section{Model integration and linearisation}

As derived in Eq. (19b), the Nash-type formulation leads to a nonlinear optimisation problem. Another non-linear equation Eq. (1a) determines profit of EV sector which are dependent on two continuous variables i.e., retired batteries' price and capacity $\left(C A P^{\mathrm{RB}}\right.$ and price $\left.{ }^{\mathrm{RB}}\right)$. Here, we apply two programming approaches to linearise the framework as a MILP optimisation model [35].

Modelling technique I - Equivalent linear formulation. To linearise the Eq. (1a), we adopt piecewise linearisation approach [36]. The price of retired batteries is discretised to $\mathrm{k}$ levels by introducing a parameter $\stackrel{\mathrm{RB}}{=}$

$\overline{\text { price }}_{\mathrm{k}}$ in Eq. (20a), where the number of $k$ is a user-defined parameter. $X_{k}$ represents a binary variable. As defined in Eq. (20b), no more than one discrete price level can be selected in each solution.

price $^{\mathrm{RB}}=\sum_{k} \overline{\overline{\text { price }}}_{k}^{\mathrm{RB}} X_{k}$

$\sum_{k} X_{k}=1$

Then, $C A P^{\mathrm{RB}}$ price ${ }^{\mathrm{RB}}$ in Eq. (1a) can be reformulated as Eq. (21), determined by a continuous variable $\left(C A P^{\mathrm{RB}}\right)$ and a binary variable $\left(X_{k}\right)$.

$C A P^{\mathrm{RB}}$ price $^{\mathrm{RB}}=C A P^{\mathrm{RB}} \sum_{k} \overline{\overline{\text { price }}}_{k}^{\mathrm{RB}} X_{k}$

By further introducing a variable $Z_{k}$ and a series of inequality constraints in Eq. (22a)-(e), $C A P^{\mathrm{RB}}$ price ${ }^{\mathrm{RB}}$ can be replaced by $\sum_{\mathrm{k}} \overline{\overline{\text { price }}}_{\mathrm{k}} \mathrm{Z}_{\mathrm{k}}$ and linearised.

$Z_{k}=C A P^{\mathrm{RB}} X_{k}$

$Z_{k} \leq \overline{C A P^{\mathrm{RB}}} X_{k}$

$Z_{k} \leq C A P^{\mathrm{RB}}$

$Z_{k} \geq C A P^{\mathrm{RB}}-\left(1-X_{k}\right) \overline{C A P^{\mathrm{RB}}}$

$Z_{k} \geq 0$

Modelling technique II - Separable programming. The nonlinear nonconvex optimisation problem in Eq. (19b) is transformed to convex optimisation by adopting the linearisation approach ${ }^{35}$. Assuming $f(x)$ is a continuous convex function with a variable $x$, it can be approximated via a piecewise linear function of $\mathrm{f}\left(x_{q}\right)$ with $A$ grid points as shown in Eq. (23a). $\lambda_{q}$ is a set of special order variables with only two adjacent nodes taking non-zero values $[36,37]$.

$f(x)=\sum_{q=1}^{A} \lambda_{q} \mathrm{f}\left(x_{q}\right)$

$\sum_{q=1}^{A} \lambda_{q}=1$

$\lambda_{q} \geq 0 \quad \forall q$

As mentioned in Model framework, the Nash-type objective function of Eq. (19b) leads to a non-linear problem which is difficult to solve. Here it was firstly reformatted as Eq. (24a) and further transformed to a logarithmic differentiation as formulated in Eq. (24b).

$\max \phi=\prod_{p}\left(\pi_{p}-\pi_{p}^{\mathrm{L}}\right)$

$\max \ln \phi=\sum_{p} \ln \left(\pi_{p}-\pi_{p}^{\mathrm{L}}\right)$

where the superscript of $\mathrm{L}$ denotes the lower bound of profit for each sector.

Therefore, the objective is to maximise $\hat{\phi}$ as demonstrated in Eq. (25a)-(e), while $\pi_{p q}$ is constrained by Eq. (26a)-(c) for each player.

$\max \hat{\phi}=\sum_{p} \sum_{q}^{A} \lambda_{p q} \theta_{p q}$

$\hat{\phi} \equiv \ln \phi$ 
$\theta_{p q}=\ln \left(\pi_{p q}-\pi_{p}^{\mathrm{L}}\right)$

$\sum_{q=1}^{A} \lambda_{p q}=1 \quad \forall p \in\{\mathrm{EV}, \mathrm{DES}, \mathrm{D} \mathrm{R}\}$

$\lambda_{p q} \geq 0 \quad \forall p, q$

where $\theta_{p q}$ is defined as a parameter, $\pi_{p q}$ is the discrete profit at $q$ level for each player $p$.

$$
\sum_{q}^{A} \lambda_{\mathrm{EV}, q} \pi_{\mathrm{EV}, q}=C A P^{\mathrm{RB}} \text { price }^{\mathrm{RB}}-C A P^{\mathrm{RB}} \mathrm{C}_{\mathrm{EV}}=\sum_{k} \overline{\overline{\operatorname{price}}}_{k}^{\mathrm{RB}} Z_{k}-C A P^{\mathrm{RB}} \mathrm{C}_{\mathrm{EV}}
$$

$$
\begin{aligned}
& \sum_{q}^{A} \lambda_{\mathrm{DES}, q} \pi_{\mathrm{DES}, q}=C_{\mathrm{DES}}^{\mathrm{NB}}-C_{\mathrm{DES}}^{\mathrm{RB}} \\
& \sum_{q}^{A} \lambda_{\mathrm{D} \mathrm{R}, q} \pi_{\mathrm{D} \mathrm{R}, q}=C A P^{R B} \times \text { benef it }^{\mathrm{D} \mathrm{R}}
\end{aligned}
$$

Based on above linearisation programming approach, it is vital to determine the upper and lower bounds for the $\theta_{p q}$ values. For the EV sector, the upper bound of $\theta_{p q}$ is derived by maximising the sales price and the sold capacity, the lower bound is determined by minimising sales price and capacity. For the DES sector, the upper bound is obtained by solving DES model with a minimum retired batteries price, and the lower bound reaches zero when the retired batteries price is equal to that of new batteries. For the D\&R sector, the upper and lower bound values depend on capacity.

By linearisation, the final derived MILP model was built and solved in GAMS 25.0.3 [38], using the CPLEX solver [39] on an $8 \times 12-$ Core Xeon X5675 clusters with 48GB RAM. The number of variables is 30,544 including 15,738 binary variables; the number of constraints is 40,217. The CPU times vary between 30 and $90 \mathrm{~min}$. The optimality gap is set to $1 \%$, and all other settings remain at default values.

\section{Model validation}

Although we present a linear equivalent for the non-linear problem of Eq. (19b), a gap still exists between the non-linear term and the linear equivalent, which depends on the number of discrete levels $q$. Hence, the selection of $q$ may affect the results. To validate the proposed model, we tested the profit fluctuations with different linearisation pieces $(q)$ of profit. Detailed validation procedure is given in Supplementary SI-2. With the discretisation level $q$ above 25, the results were found to be stable, i.e., almost half of the total profit (49\%) is allocated to the DES sector, the EV sector shares $45 \%$ of the total profit, and the remaining $6 \%$ is allocated to the D\&R sector. This is consistent with the fairest solution we presented in the Case study and optimal solutions. Meanwhile, the retired batteries price (price $\left.e^{\mathrm{RB}}\right)$ is discretised into 50 levels $(k=50)$, which produced stable results.

\section{Declaration of Competing Interest}

The authors declare no competing interests.

\section{Data availability}

The input and output data that support the findings of this study are available from the corresponding author upon reasonable request.

\section{Acknowledgment}

We thank Dr. Di Zhang and Dr. Qingyuan Kong from Imperial College London for discussion on methodology, Mr. Zhihui Zhang from Xiamen
University for figure elaboration, and Ms. Ellen Piercy from Kings College London for proof-reading. M.G. would like to acknowledge the UK Engineering and Physical Sciences Research Council (EPSRC) for providing financial support for research under project 'Resilient and Sustainable Biorenewable Systems Engineering Model' [EP/N034740/1].

\section{Author Contributions}

R.J., J.W. and M.G. designed the study. R.J. and J.W. collected the data and built the model. R.J. and M.G. analysed the results. R.J. drafted the paper. N.S. and M.G. edited the paper. M.G. provided the fund.

\section{Supplementary materials}

Supplementary material associated with this article can be found, in the online version, at doi:10.1016/j.adapen.2020.100002.

\section{Reference}

[1] Crabtree G. The coming electric vehicle transformation. Science 2019;366:422-4.

[2] Yun L, Linh D, Shui L, Peng X, Garg A, Le MLP, et al. Metallurgical and mechanical methods for recycling of lithium-ion battery pack for electric vehicles. Resour Conserv Recycl 2018;136:198-208.

[3] Huang Z, Xie Z, Zhang C, Chan SH, Milewski J, Xie Y, et al. Modeling and multi-objective optimization of a stand-alone PV-hydrogen-retired EV battery hybrid energy system. Energy Convers Manag 2019;181:80-92.

[4] Wu Y, Yang L, Tian X, Li Y, Zuo T. Temporal and spatial analysis for end-of-life power batteries from electric vehicles in China. Resour Conserv Recycl 2020;155:104651.

[5] Harper G, Sommerville R, Kendrick E, Driscoll L, Slater P, Stolkin R, et al. Recycling lithium-ion batteries from electric vehicles. Nature 2019;575:75-86.

[6] Richa K, Babbitt CW, Nenadic NG, Gaustad G. Environmental trade-offs across cascading lithium-ion battery life cycles. Int J Life Cycle Assess 2015;22:66-81.

[7] Chen M, Ma X, Chen B, Arsenault R, Karlson P, Simon N, et al. Recycling end-of-life electric vehicle lithium-ion batteries. Joule 2019;3:2622-46.

[8] EditorialRecycle spent batteries. Nat Energy 2019;4:253.

[9] BOSCH. A second life for used batteries. https://www.bosch-pressede/pressportal/ de/en/a-second-life-for-usedbatteries-64192html. 2016; [Access: 2019/1/20].

[10] NISSAN. Nissan and 4R energy partner with green charge networks for commercial energy storage featuring second-life electric vehicle batteries. https:// nissannewscom/en-US/nissan/usa/releases/nissan-and-4r-energy-partner-withgreencharge-networks-for-commercial-energy-storage-featuring-second-life-electricvehicle-batteries. 2015; [Access: 2019/1/20].

[11] RENAULT. Renault and powervault give EV batteries a "second-life" in smart energy deal. https://mediagrouprenaultcom/global/en-gb/media/pressreleases/92203/ renault-et-powervault-donnent-une-secondevie-aux-batteries-des-vehiculeselectriques1. 2017; [Access: 2019/1/20].

[12] Xinhuanet. BAIC and GCE strategic cooperation in retired battery recycling and utilisation field. http://www.xinhuanetcom/auto/2018-05/09/c 1122803694htm. 2018; [Access:2019/1/20] [In Chinese].

[13] Heymans C, Walker SB, Young SB, Fowler M. Economic analysis of second use elec tric vehicle batteries for residential energy storage and load-levelling. Energy Policy 2014;71:22-30.

[14] Li S, He H, Chen Y, Huang M, Hu C. Optimization between the PV and the retired EV battery for the residential microgrid application. Energy Proc 2015;75:1138-46.

[15] Tang Y, Zhang Q, McLellan B, Li H. Study on the impacts of sharing business models on economic performance of distributed PV-battery systems. Energy 2018;161:544-58.

[16] Assunção A, Moura PS, de Almeida AT. Technical and economic assessment of the secondary use of repurposed electric vehicle batteries in the residential sector to support solar energy. Appl Energy 2016;181:120-31.

[17] Han X, Liang Y, Ai Y, Li J. Economic evaluation of a PV combined energy storage charging station based on cost estimation of second-use batteries. Energy 2018;165:326-39.

[18] Gur K, Chatzikyriakou D, Baschet C, Salomon M. The reuse of electrified vehicle batteries as a means of integrating renewable energy into the European electricity grid: a policy and market analysis. Energy Policy 2018;113:535-45.

[19] Cusenza MA, Guarino F, Longo S, Mistretta M, Cellura M. Reuse of electric vehicle batteries in buildings: an integrated load match analysis and life cycle assessment approach. Energy Build 2019;186:339-54.

[20] Canals Casals L, Barbero M, Corchero C. Reused second life batteries for aggregated demand response services. J Clean Prod 2019;212:99-108.

[21] Tang Y, Zhang Q, Li Y, Li H, Pan X, McLellan B. The social-economic-environmental impacts of recycling retired EV batteries under reward-penalty mechanism. Appl Energy 2019;251:113313

[22] Jing R, Xie MN, Wang FX, Chen LX. Fair P2P energy trading between residential and commercial multi-energy systems enabling integrated demand-side management. Appl Energy 2020;262:114551.

[23] Jing R, Wang M, Zhang Z, Wang X, Li N, Shah N, et al. Distributed or centralized? Designing district-level urban energy systems by a hierarchical approach considering demand uncertainties. Appl Energy 2019;252:113424.

[24] Nash J. Non-cooperative games. Ann Math 1951;54:286-95. 
[25] Nash JF. Equilibrium points in n-person games. In: Proceedings of the National Academy of Sciences, 36; 1950. p. 48.

[26] de Chalendar JA, Glynn PW, Benson SM. City-scale decarbonization experiments with integrated energy systems. Energy Environ Sci 2019;12:1695-707.

[27] EnergyTrend. How to deal with retired batteries. In: https://www.energytrend.cn/news/20180720-34379.html, editor. 2018.

[28] Ningde-Era. Ningde era official website. In: https://www.catlbattery.com/, editor. 2019.

[29] Nykvist B, Nilsson M. Rapidly falling costs of battery packs for electric vehicles. Nat Clim Chang 2015;5:329-32.

[30] SSRI. In-depth research report on power lithium battery recycling industry. In: https://www.docin.com/p-2255759257.html, editor. 2017.

[31] Gaines L. Profitable recycling of low-cobalt lithium-ion batteries will depend on new process developments. One Earth 2019;1:413-15.

[32] Guo M. Multi-scale system modelling under circular bioeconomy. In: Friedl A, Klemeš JJ, Radl S, Varbanov PS, Wallek T, editors. Computer aided chemical engineering. Elsevier; 2018. p. 833-8.
[33] Jing R, Kuriyan K, Lin J, Shah N, Zhao Y. Quantifying the contribution of individual technologies in integrated urban energy systems - a system value approach. Appl Energy 2020;266:114859.

[34] Jing R, Kuriyan K, Kong Q, Zhang Z, Shah N, Li N, et al. Exploring the impact space of different technologies using a portfolio constraint based approach for multi-objective optimization of integrated urban energy systems. Renew Sustain Energy Rev 2019;113:109249.

[35] Gjerdrum J, Shah N, Papageorgiou LG. Fair transfer price and inventory holding policies in two-enterprise supply chains. Eur J Oper Res 2002;143:582-99.

[36] Zhang D, Samsatli NJ, Hawkes AD, Brett DJL, Shah N, Papageorgiou LG. Fair electricity transfer price and unit capacity selection for microgrids. Energy Econ 2013;36:581-93.

[37] Gjerdrum J, Shah N, Papageorgiou LG. Transfer prices for multienterprise supply chain optimization. Ind Eng Chem Res 2001;40:1650-60.

[38] GAMS. A User's Guide. GAMS development corporation; 2006.

[39] IBM. CPLEX optimization studio. 2019. 